genommen wird. Eine gewisse weitere Vermehrung könnte sich noch infolge der Einwirkung der intramolekularen Kräfte auf die Ionisierungsspannung ergeben. Auf der anderen Seite rühren die zusätzlichen primären Ionisationen sicherlich von „optischen " Größen her, und die entstandenen Sekundärelektronen können nur ganz geringfügige kinetische Energien besitzen. Wenn es also richtig ist ${ }^{20}$, daß die meist zur Untersuchung gelangenden biologischen Effekte auf einer kumulativen primären Wirkung (Zusammenwirkung verschiedener Anregungen und Ionisationen oder auch vielleicht Entstehung einer Punktwärme) beruhen, so kann ein großer Teil der „optischen“ Stöße (die energiearmen), wenn sie einzeln im strahlenempfindlichen Volumen auftreten, praktisch keine Wirksamkeit besitzen.

Damit entfällt aber auch die oben aufgezeigte Schwierigkeit. Es ist keineswegs notwendig, einen grundsätzlichen Unterschied zwischen Anregungen zu machen, die durch Elektronenstoß erzeugt werden und solchen, die durch Wiedervereinigung entstehen. Eine ins Gewicht fallende Wirkungs-Wahrscheinlichkeit besitzen offensichtlich grundsätzlich nur primäre

19 Nach der heute ganz allgemein anerkannten Auffassung wird die Inaktivierung der Enzyme eingeleitet durch eine Umordnung von Wasserstoffbrücken und Umfaltung von Polypeptidketten in einem engbegrenzten Bezirk. Es ist klar, daß hierfür eine gewisse Energie-Konzentration not-
Ionisationen mit einer bestimmten kinetischen Energie, vielleicht solche, die in der Umgebung mindestens eine Anregung hervorrufen, bevor sie zu dem positiven Ion zurückkehren.

Mit diesen Bemerkungen wird also keineswegs die große grundsätzliche Bedeutung des Ergebnisses von Pollard und Mitarbb. über die Inaktivierung der Enzyme durch energiereiche Strahlen herabgesetzt. Es erscheint vielmehr durchaus gerechtfertigt, bei Anwendung von energiereichen Elektronen oder von $\gamma$-Strahlen von vornherein von den sehr energiearmen primären Ionisationen, welche keine Möglichkeit zu einer kumulativen Wirkung besitzen, abzusehen. Die Zahl der primären Elementarakte, welche dabei zur Auslösung einer kumulativen Wirkung imstande sind, erhält man jedenfalls, indem man die absorbierten Dosen oder die Bremsvermögen durch 110 oder auch $100 \mathrm{eV}$ dividiert. Bei Anwendung von energiereichen Elektronen oder $\gamma$-Strahlen, bei denen ein Zusammenwirken von primären Ionisationen nicht möglich ist, dürfte also der mittlere Energieaufwand pro effektive primäre Ionisation 110 oder $100 \mathrm{eV}$ betragen.

wendig ist, über deren Schwellenwert ist jedoch eine quantitative Aussage wohl nur schwer möglich. Zu dem ganzen Vorgang vgl. Franck und Platzmann 21.

20 J. Franck u. R. Platzmann, in: A. Holländer, Radiat. Biol. B. I, New York 1954, S. 191.

\title{
Zur Frage der Darstellbarkeit von Fibrinogen aus menschlidem Plasma mit Hilfe der Immuno-Elektrophorese nach Grabar
}

\author{
Von H. Götz und F. Scheiffarth \\ Aus der Medizinischen Universitäts-Klinik Erlangen (Direktor: Prof. Dr. N. Henning) \\ (Z. Naturforschg. 14 b, 37-41 [1959]; eingegangen am 21. Juli 1958)
}

\begin{abstract}
An einem Untersuchungsgut von insgesamt 16 Plasmen und den entsprechenden Seren (von 10 Gesunden sowie 6 Kranken mit Erhöhung des Fibrinogengehaltes) wurde mit Hilfe der ImmunoElektrophorese im Gelmilieu die Darstellbarkeit auch von Fibrinogen unter Beweis gestellt: Fibrinogen findet sich bei der Agar-Elektrophorese als einheitliche Fraktion im Bereich der Auftragstelle. Es läßt sich gegenüber benachbarten Fraktionen, wie $\alpha$ - bzw. $\beta$-Globulin-Fraktionen eindeutig abgrenzen.
\end{abstract}

Im Rahmen der Bemühungen um eine Definierung der mit der Immuno-Elektrophorese erzielbaren Komponenten normaler und pathologischer Seren haben wir uns die Frage vorgelegt, inwieweit das Fibrinogen aus menschlichem Plasma elektrophoretisch im Gelmilieu zur Darstellung gelangt. Daß bisher keine entsprechenden Untersuchungen vor- genommen wurden, liegt im wesentlichen an der bereits bekannten Erfahrungstatsache, daß großmolekulare und extrem asymmetrisch aufgebaute Eiweißmoleküle wie das Fibrinogen, das Agargitter schlecht oder überhaupt nicht zu passieren vermögen, wodurch die elektrophoretische Wanderung bzw. Trennbarkeit im Gel illusorisch wird. Wir haben in vor- 
liegender Arbeit trotzdem versucht, unter Verwendung verschiedener Antinormalseren * sowie eines Anti-Plasma-Kaninchenserums P, Serum und Plasma von Gesunden und in einigen Fällen von Kranken miteinander zu vergleichen. Es sollte dabei beurteilt werden, ob sich das Fibrinogen immunologisch als einheitliche Komponente darstellt, und ob bei pathologischer Fibrinogen-Vermehrung grundsätzliche Abweichungen von den physiologischen Verhältnissen aufzuweisen wären.

\section{Methodik und Versuchsanordnung}

Serum und Plasma von insgesamt 10 gesunden Personen und von 6 Kranken mit erheblich beschleunigter Senkung und papierelektrophoretisch nachweisbarer $\varphi$-Vermehrung wurden immuno-elektrophoretisch analysiert.

\section{Plas magewinnung}

Da für die Papierelektrophorese - die wir hier vergleichsweise mitlaufen ließen - nach unseren Erfahrungen 7,8 nur Heparin zur Gerinnungsverhinderung des Blutes geeignet ist, haben wir grundsätzlich zur Plasmagewinnung Heparin **, und zwar $0,1 \mathrm{ml}$ auf $2,0 \mathrm{ml}$ Blut, verwendet.

\section{Elektrophorese im Gelmilieu}

In vorliegender Arbeit wurden die einfache Gel-Elektrophorese sowie die Immuno-Elektrophorese nach $\mathrm{G} \mathrm{r}$ a b a r (Original-Makro-Elektrophorese) angewandt. Auf methodische Einzelheiten, die im französischen Schrifttum vor Jahren schon ausführlich beschrieben wurden ${ }^{5,6,14}$, wurde auch von uns bereits mehrmals hingewiesen ${ }^{4,9}$. Eine Wiedergabe des Verfahrens an dieser Stelle erübrigt sich also. Zur Anfärbung der Proteinanteile - sowohl bei der einfachen als auch bei der Immuno-Elektrophorese - wurde Amidoschwarz $10 \mathrm{~B}$ gewählt.

\section{Herstellung der Immunseren}

Als Immunseren kamen jeweils 2 verschiedene Immunseren, und zwar Anti-Human-Normalserum-Immunserum sowie ein Anti-Humanplasma-Immunserum vom Kaninchen zur Anwendung. Die Sensibilisierung erfolgte nach nachstehendem Schema: 1., 5., 9., 13. und 17. Tag je eine i.v. Injektion von $1,0 \mathrm{ml}$ eines jeweils frischen Mischserums bzw. Mischplasmas von 3 Gesunden. Abnahme des Immunserums 10-14 Tage nach der letzten Injektion.

4. Plasma-Elektrophorese auf Filtrier-
papier

Hierzu wurde die übliche Papier-Elektrophorese nach $\mathrm{G}$ r a s s m a n $\mathrm{n}$ und $\mathrm{H}$ a $\mathrm{n}$ ig vorgenommen, wobei an Stelle des Serums das mit Heparin gewonnene Plasma aufgetragen wurde. Ein Zusatz von Heparin zur Pufferlösung, wie wir es früher empfohlen haben ${ }^{8}$, hat sich inzwischen als überflüssig erwiesen.

\section{Die Versuchsanordnung}

Im engeren Sinne bestand sie darin, daß jeweils Serum und Plasma ein und desselben Spenders agarelektrophoretisch und papier-elektrophoretisch aufgetrennt wurden, und daß bei der Immuno-Elektrophorese nach Abschluß des Trennvorganges in je einen Kanal neben dem Serum und dem Plasma Anti-Normalserum $1: 1$ mit physiologischer $\mathrm{NaCl}$ verdünnt, und in den zwischen Serum und Plasma gelegenen Kanal AntiPlasmaserum, ebenfalls $1: 1$ mit physiol. $\mathrm{NaCl}$ verdünnt, eingelassen wurden (vgl. auch Abb. 2 b). Ferner wurden in 3 Fällen aus dem Anti-Plasmaserum die Antiserum-Antikörper an ein Normalserum adsorbiert, so daß ausschließlich die Anti- $\varphi$-Komponente zurückblieb, die dann einem elektrophoretisch aufgetrennten Plasma entgegengesetzt wurde.

\section{Ergebnisse}

Die Ergebnisse lassen sich an Hand der einzelnen Abbildungen besprechen:

1. Bei einfacher Elektrophorese im Agargel finden sich im Bereich der Auftragsstelle beim Plasma Proteinanteile, die im Serum vermißt werden; besonders deutlich wird dies im Falle von pathologisch vermehrtem $\varphi$-Globulin (Abb. 1).

2. Mit der Immuno-Elektrophorese läßt sich in der Nähe der Auftragsstelle mit dem Anti-Plasma-

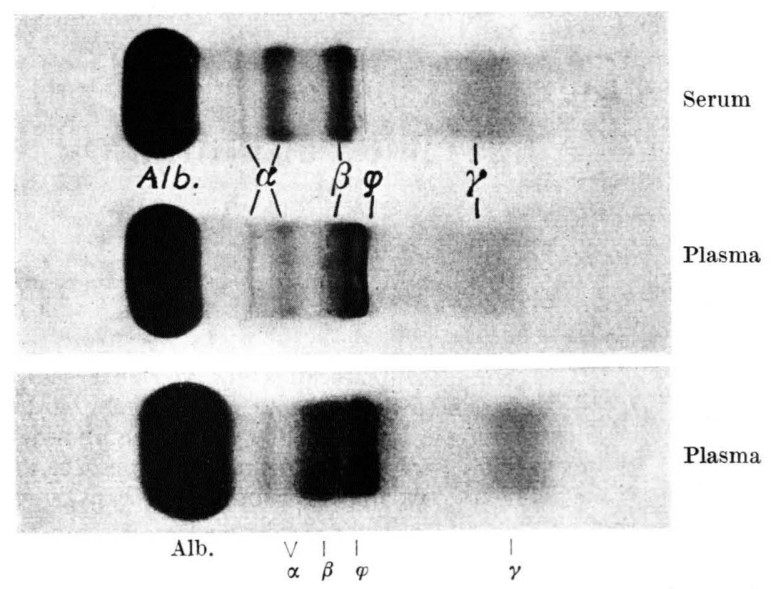

Abb. 1. Sie zeigt die einfache Elektrophorese im Agargel, oben von Serum und Plasma eines Gesunden, darunter das Plasma einer Kranken mit erhöhtem Fibrinogengehalt. Man erkennt, insbesondere bei dem pathologischen Plasma, deutlich die dem Fibrinogen entsprechende Protein-Anreicherung im Bereich der Auftragstelle.

\footnotetext{
* Anti-Normalserum-Immunseren vom Kaninchen. * Elheparin, Luitpold-Werk-München.
} 


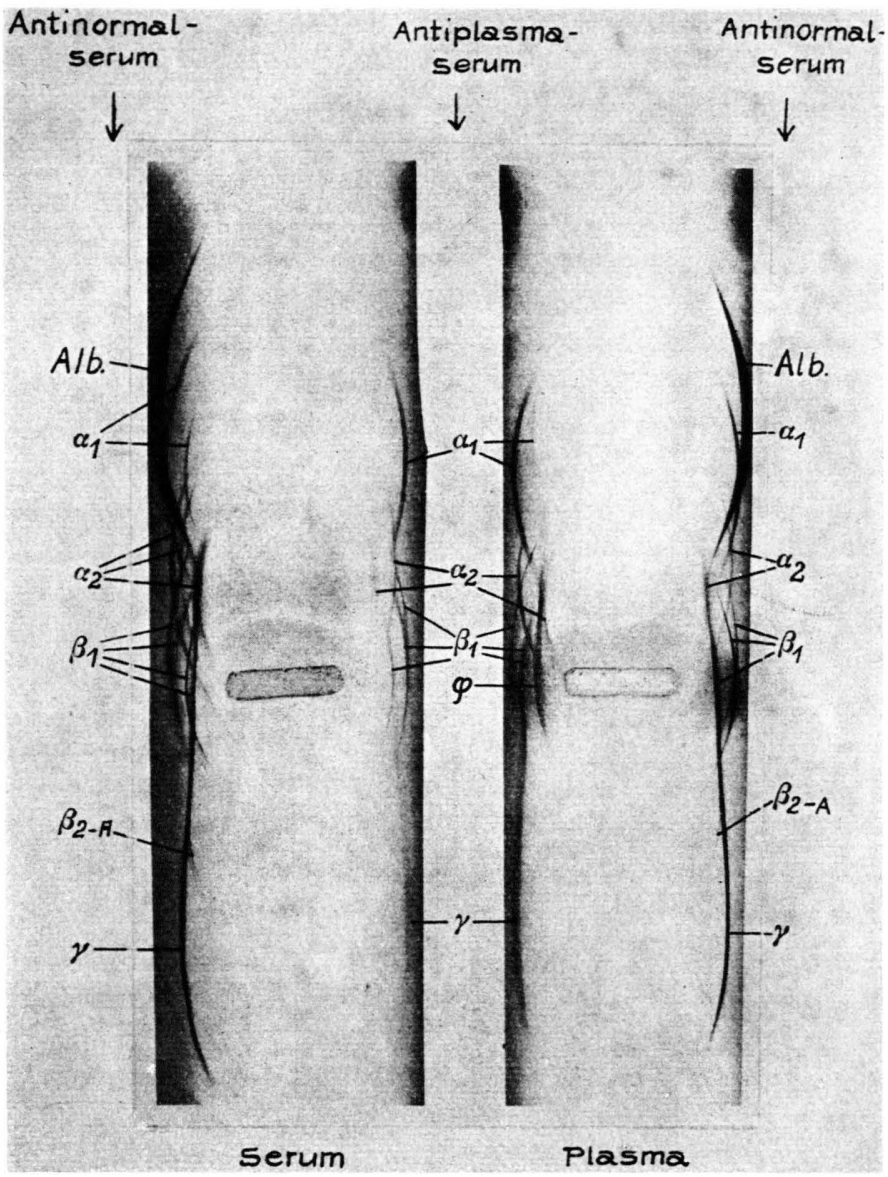

Abb. 2 a. Sie zeigt die Immuno-Elektrophorese, links des Serums und rechts des entsprechenden Plasmas einer Kranken mit rel. FibrinogenVermehrung. In den Kanälen links bzw. rechts außen befand sich AntiHumanserum, im Kanal zwischen Serum und Plasma Anti-Plasmaserum. Man erkennt deutlich die Unterschiede zwischen den Präzipitations-Linien des Serums und des Plasmas, wobei hier auffällt, daß mit Anti-Humanserum bei Serum mehr Präzipitations-Linien nachweisbar sind als bei Plasma. Die $\varphi$-Fraktion des Plasmas ist mit dem spezifischen AntiPlasmaserum sehr gut darstellbar.

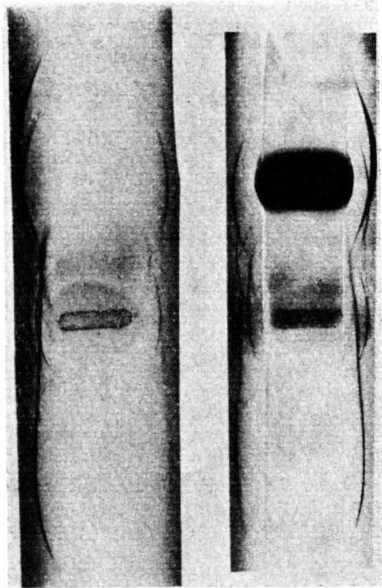

Abb. 2 b. Hier zeigt sich in Ergänzung zu Abb. 2 a die einfache sowie die entsprechende Immuno-Elektrophorese von Plasma in Agar. serum und auch mit Anti-Normalserum eine im allgemeinen vom Startpunkt aus kathodenwärts verlaufende, deutlich ausgeprägte Präzipitations-Linie nachweisen, die in einem Fall außerdem offensichtlich Beziehung aufnimmt zur $\alpha_{2}$-Makroglobulin-Fraktion (Abb. 2 a, Abb. 3). Außerdem erscheint bei der Diffusion gegen Plasma eine der $\beta$-Fraktionen etwas stärker ausgeprägt zu sein als bei der Diffusion gegen Serum. Mit den Komponenten des Serums bildet das Anti-Plasmaserum diese oben beschriebene Präzipitations-Linie um den Auftragsstrich nicht aus. Nach Absorption des Anti-Plasmaserums an Normalserum läßt sich mit dem verbliebenen Anti- $\varphi$-Serum gegen elektrophoretisch aufgetrenntes Plasma im Bereich des Startpunktes eine einheitliche, in Richtung Kathode ausgezogene Präzipitations-Linie nachweisen (Abb. 3).

Vergleicht man die mit dem Anti-Normalserum ausgebildeten Präzipitations-Linien bei Serum und Plasma, so lassen sich im großen und ganzen keine wesentlichen Unterschiede erkennen. Allerdings vermißt man in zwei der untersuchten Normalfälle im Serum (gegenüber Plasma) eine $\alpha_{1^{-}}$, eine $\alpha_{2^{-}}$sowie eine $\beta_{1}$-Komponente. In vier weiteren Fällen - darunter drei pathologische - waren gerade im Plasma weniger Präzipitations-Linien ausgefallen; insbeson- 


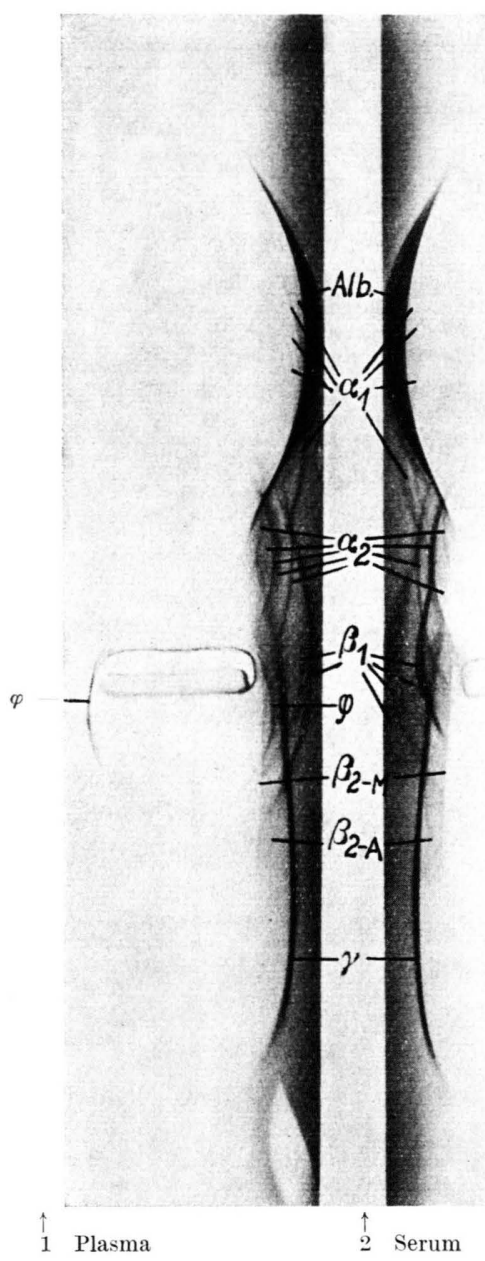

Abb. 3. Isolierte Darstellung der $\varphi$-Fraktion im Plasma. Die Abbildung zeigt die Immuno-Elektrophorese, links eines Plasmas und rechts des entsprechenden Serums. Im seitlichen Kanal No. 1 befand sich ein Anti-Plasmaserum, welches vorher mit Normalserum abgesättigt worden war, bei 2 Anti-Normalserum. Die $\varphi$-Fraktion ist deutlich zu erkennen.

dere fehlte eine der $\beta$-Globulin-Fraktionen. In den übrigen Paralleluntersuchungen konnten keine Unterschiede festgestellt werden.

3. Mit der Papier-Elektrophorese läßt sich in allen Fällen im Plasma an typischer Stelle, d. h. zwischen $\beta$ - und $\gamma$-Globulin die für das Fibrinogen angesehene $\varphi$-Fraktion nachweisen (Abb. 4).

\section{Diskussion}

Die Tatsache, daß im Gegensatz zur Papier-Elektrophorese die der $\varphi$-Fraktion zuzuordnende Proteinkomponente bei der Elektrophorese im Gelmilieu quasi auf dem Startpunkt liegen bleibt, beweist, daß
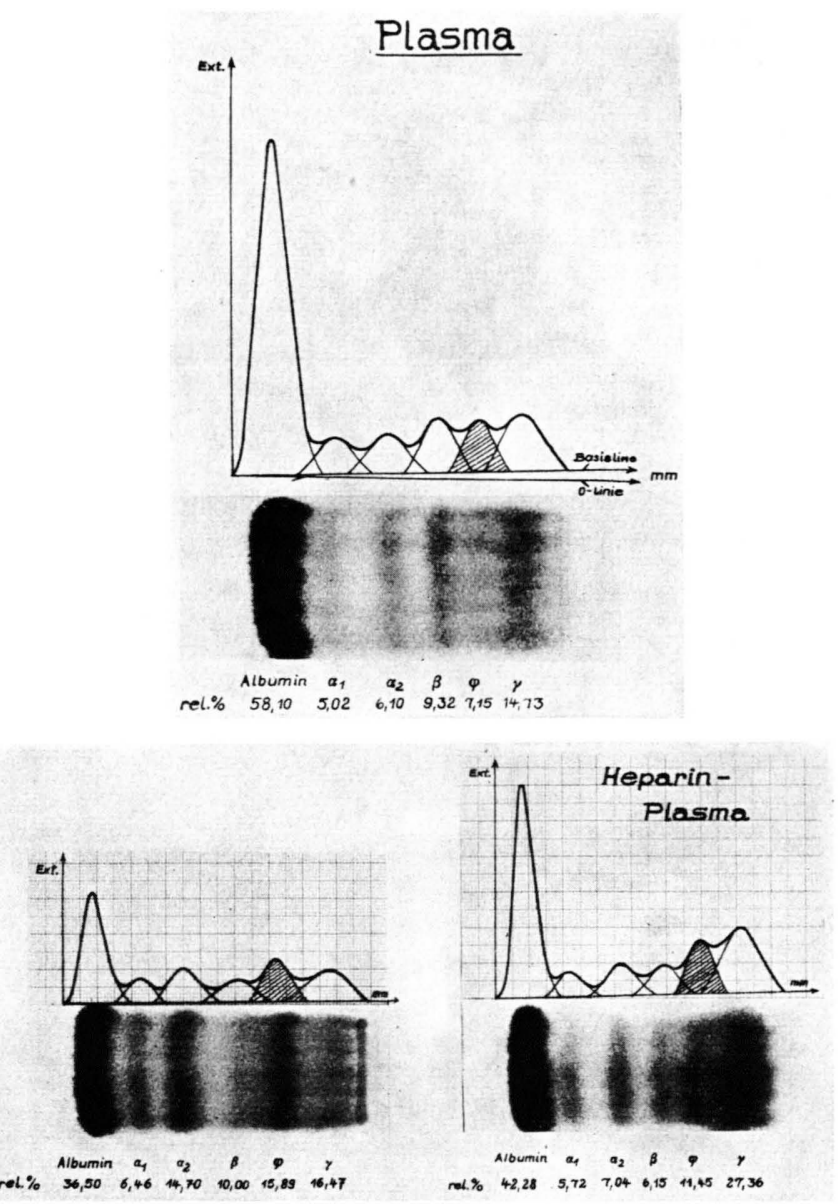

Abb. 4. Sie i eigt Streifen und Diagramme von Papier-Elektrophoresen eines Normalplasmas (oben) sowie zweier pathologischer Plasmen mit deutlicher Vermehrung der $\varphi$-Fraktion (unten). Die Fibrinogen-Fraktion projiziert sich in allen Fällen an typischer Stelle zwischen $\beta$ - und $\gamma$-Globulin.

Fibrinogen im Agar nicht zu wandern vermag. Die Fraktion als solche ist jedoch, wie insbesondere aus den immuno-elektrophoretischen Ergebnissen zu ersehen, eindeutig darstellbar und als Fibrinogen definierbar.

Die Frage, inwieweit die Fibrinogen-Fraktion im Plasma eine einheitliche Komponente darstellt oder nicht, kann auf Grund unserer Untersuchungen dahingehend beantwortet werden, daß sicher nur ein Protein vorliegt. Daß sich die $\varphi$-Fraktion in einem von uns beobachteten Fall relativ weit in den $\alpha$-Bereich erstreckt, scheint an den $p_{\mathrm{H}}$-Verhältnissen des damals verwendeten Agars zu liegen oder aber mit der relativ starken Fibrinogenvermehrung dieses Plasmas zusammenzuhängen. Andere Autoren, wie Schultze und Schwick ${ }^{10}$ sowie Seligmann und Mit- 
arb. ${ }^{11,12}$, haben, allerdings von anderen Gesichtspunkten ausgehend, grundsätzlich das Fibrinogen an gleicher Stelle lokalisiert gefunden, d. h. auch sie konnten keine Wanderung dieser Fraktion im Agargel beobachten.

Das in einigen Fällen unterschiedliche Ergebnis zwischen Serum und Plasma bei Untersuchungen mit Anti-Normalserum, d. h. das Fehlen von Präzipitations-Linien im $\alpha$ - und $\beta$-Globulinbereich, bald im Serum, bald im Plasma kann vorerst nicht einheitlich erklärt werden *. Auch die wechselnd gute Darstellung der $\varphi$-Fraktion kann zunächst nur mit der unterschiedlichen Qualität der von uns verwendeten Immunseren bzw. mit dem unterschiedlichen Fibrinogengehalt der untersuchten Plasmen in Zusammenhang gebracht werden. Aus den beschriebenen zwei Beobachtungen, bei welchen im Serum weniger Komponenten nachweisbar waren als im Plasma, ließe sich auf Grund theoretischer Überlegung folgern, $\mathrm{da} ß$ es sich bei den fehlenden Proteinsystemen um Gerinnungsfaktoren handelt, die im Plasma noch enthalten sein müßten. Tatsächlich konnten z. B. wenn auch mit anderer Methodik - das aus Rinderplasma gewonnene Prothrombin als Eiweißkörper mit Eigenschaften der $\alpha$-Globuline identifiziert werden ${ }^{13}$. Nach CoHn und Mitarbb. ${ }^{1,2,3}$ findet sich humanes Prothrombin, ebenso wie Thrombin, in der Fraktion $\mathrm{III}_{2,3}$ der Methode 6, was etwa dem elektrophoretischen $\beta$-Bereich entspricht. Bei den vier Fällen, bei welchen gerade das Plasma weniger Präzipitations-Linien aufwies als das Serum, handelte es sich in dreien davon um relativ starke Fibrinogen-Vermehrungen bei Kranken mit erheblichen

* Derzeit laufende Untersuchungen an einem größeren klinischen Material sollen zur weiteren Klärung dieser Frage beitragen.

1 E. J. Сонn, Amer. Sci. 10, 55 [1945].

2 E. J. Cohn, J. L. Oncley, L. E. Strong, W. L. Hughes U. S. H. Armstrong, jr., J. clin. Invest. 23, 417 [1944].

3 E. J. Cohn, F. R. N. Gurd, D. M. Surgenor, B. A. Barnes, R. K. Brown, G. Derouaux, J. M. Gillepsie, F. W. Kahnt, W. F. Lever, C. H. Liu, D. Mittelman, R. F. Mouton, K. Schmid u. E. Uroma, J. Amer. chem. Soc. 72, 465 [1950].

${ }^{4}$ H. Götz, G. Berg u. F. Scheiffarth, Z. Immunitätsforsch. exp. Therap. 114, 72 [1957].

5 P. Grabar, Bull. Soc. Chim. biol. 36, 65 [1954]; Zbl. Bakteriol., Parasitenkunde, Infektionskrankh. Hyg., I. Abt., Orig. 164, 15 [1955].

6 P. Grabar u. C. A. Williams, Biochim. biophysica Acta [Amsterdam] 10, 193 [1953]; 17, 67 [1955].
Dysproteinämie-Phänomenen. Hier könnte das angereicherte makromolekulare $\varphi$-Protein im Plasma komplex benachbarte ( $\beta$-Globuline!) oder in ihren Proteineigenschaften ähnliche ( $\alpha_{2}$-Makroglobulin,

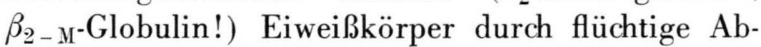
sorption an ihrer elektrophoretischen Wanderung hindern, wodurch deren Nachweis erschwert würde. Im Hinblick auf die übrigen Untersuchungsbefunde jedoch, wonach zwischen Serum und Plasma keine wesentlichen Unterschiede offensichtlich wurden, können die oben genannten Erklärungen lediglich Diskussionspunkte und keine endgültigen Schlußfolgerungen darstellen.

Somit kann festgestellt werden, daß sich mit Hilfe der hier angeführten immunologischen Technik auch Plasma in seine Komponenten differenzieren läßt, und daß auch das Fibrinogen eindeutig darstellbar ist, was gelegentlich für die Analyse pathologischer Plasmen von Interesse sein kann. Wir haben allerdings an unseren bislang erzielten Untersuchungsergebnissen pathologischer Plasmen keine grundsätzlichen Abweichungen in der Darstellung der $\varphi$-Fraktion beobachten können, Wenn man davon absieht, daß diese Fraktion im Sinne des Antigenüberschuß-Phänomens mehr oder weniger stark auspräzipitiert.

Weiterhin kann aus unseren Ergebnissen geschlossen werden, daß im Anti-Normalserum offenbar auch ein Immunkörper vorliegt, der mit Fibrinogen eine spezifische Antigen-Antikörper-Reaktion einzugehen vermag, was die immunologische Verwandtschaft des Fibrinogens mit den übrigen - makromolekularen (?) - Proteinen des Serums beweist.

7 F. Scheiffarth, Ärztl. Lab. 1955, 105.

8 F. Scheiffarth, G. Berg u. H. Götz, Hoppe-Seyler's Z. physiol. Chem. 302, 126 [1955].

9 F. Scheiffarth, H. Götz u. W. Frenger, Ärztl. Wschr. 1956, 573.

10 H. E. Schultze u. G. Schwick, Behringwerk-Mitteilungen Heft 33, 11 [1957].

11 M. Seligmann, C. R. hebd. Séances Acad. Sci. 244, 2192 [1957] ; Proc. 5th Colloq. Bruges 1957, 167.

12 M. Seligmann, B. Goudemand, A. Janin, J. Bernard u. P. Grabar, Rev. Hématol. 12, 302 [1957].

13 D. M. Surgenor, in: Blood cells and plasma proteins; edited by J. L. Tullis, Acad. Press. New York 1953, S. 61.

14 J. Uriel u. J. J. Scheidegger, Bull. Soc. Chim. biol. 37, 165 [1955]. 